\author{
한우 씨수소의 근교계수와 유효집단크기의 추정 \\ 당창권 · 이중재 · 김내수* \\ 충북대학교 축산학과
}

\title{
Estimation of Inbreeding Coefficients and Effective Population Size in Breeding Bulls of Hanwoo (Korean Cattle)
}

\author{
Chang Gwon Dang, Jung Jae Lee and Nae Soo Kim* \\ Department of Animal Science, Chungbuk National University, 52 Naesudong-ro, Heungdeok-gu, Cheongju 361-763, Korea
}

\begin{abstract}
This study was carried out to estimate average inbreeding coefficients, relatedness and effective population size of breeding bulls and to suggest optimal alternatives on problems of current Hanwoo improvement system. Data on proven and young bulls were obtained from 1,128 heads of Livestock Improvement Main Center from 1983 to 2008. Pedigree information on proven and young bulls was obtained from 3,760 heads of Korea Animal Improvement Association. Average inbreeding coefficients and average relatedness of proven and young bulls were estimated at the range of $0.04-0.07 \%, 0.10-6.82 \%$, respectively. Effective population size was estimated for 220 heads from the average rate of inbreeding of last 26 years. Average inbreeding coefficient is rising rapidly for the last two years as well as average relatedness. Effective population size was estimated for 47 heads for the last five years. These results suggest that selection criteria of proven bulls should include not only genetic evaluation of carcass performance from progeny-test, but also inbreeding and relationship coefficients, in order to maintain genetic variability of Hanwoo. In addition, effective population size should be increased by increasing the number of proven bulls.
\end{abstract}

(Key words : Inbreeding coefficients, Effective population size, Breeding bull of Hanwoo)

\section{서 론}

과거에는 표현형자료를 근거로 씨수소 선발을 하였으나, 현재는 컴퓨터의 발달로 대용량의 자료처리가 가능해지고 육종가를 추정하 는 방법들이 발달하여 예측 육종가(Estimated breeding value; $\mathrm{EBV})$ 의 정확성이 높아져 육종가를 이용하여 씨수소를 선발하고 있다. 또한 번식기술의 발달로 인공수정이 보편화되면서 적은 수의 씨수소로 전 집단의 번식이 가능하게 되어 선발강도를 높여 유전적 개량을 하고 있다. 우리나라에서도 국가단위 한우개량을 위하여 1980 년대 이전에는 축산진흥대회와 같은 품평회를 통하여 외모가 우수한 수소를 씨수소로 활용하였지만, 1980년대 이후에는 개체모 형 (Animal Model)을 이용하여 추정된 육종가를 씨수소 선발에 활용하는 당-후대검정을 하고 있다. 현재 한우 육종체계에서 이용 되는 당대검정이란 보증씨수소와 우량암소의 계획교배로 생산된 송 아지들에 체중, 체위, 사료섭취량과 사료요구율 및 외모심사에 대 하여 조사하여 가축개량총괄기관에서 정한 선발 지수식에 의한 개 체별 순위를 이용하여 후보씨수소를 선발하는 과정이고, 후대검정
이란 이 후보씨수소들의 후손을 생산하여 이 후손들의 체중, 체위, 사료섭취량과 도체조사 및 평가를 조사하여 가축개량총괄기관에서 정한 선발 지수식에 의해 평가한 후 가축개량협의회 심의를 거쳐 보증씨수소를 선발하는 과정이다. 매년 당대검정으로 40 두의 후보 씨수소를 선발한 후 후대검정에 공시하여 최종적으로 20 두의 보증 씨수소를 선발하여 농가에 정액을 공급하고 있다.

하지만 적은 수의 씨수소 정액사용은 혈연관계가 있는 개체들이 같이 선발될 가능성 또한 증가되어 세대 당 근교된 개체의 확률이 높아지고(Weigel, 2001), 씨수소 제한으로 유효집단크기 역시 작 아질 것으로 사료된다. 근교는 보통 근교퇴화로 알고 있는 개체의 성장, 비유 및 생존 능력에 감소를 가져오며, 유효집단크기도 작아 지면 개체의 유전적 다양성이 감소된다(FAO, 2004).

그러므로 본 연구는 지금까지 보증 및 후보씨수소로 선발된 씨수 소에 대하여 연도별 평균 근교 및 혈연계수를 추정하고 씨수소의 유효집단크기를 추정하여 현재 한우개량 체계의 문제를 도출하여 발전된 대안을 제시하고자 실시하였다.

* Corresponding author: Nae Soo Kim, Department of Animal Science, Chungbuk National University, 52 Naesudong-ro Heungdeok-gu, Cheongju 361-763, Korea. Tel: 82-43-261-2548, Fax: 82-43-272-2240, E-mail: rvaukim@chungbuk.ac.kr 


\section{재료 및 방법}

\section{1. 혈통자료}

본 연구에 사용된 자료는 한우개량사업소로부터 생년월일이 파악 되는 보증 및 후보씨수소 1,428 두 중에서 혈연관계가 나타나기 시 작한 1983년부터 2008년까지 1,128두의 씨수소 자료와 분석에 이 용하기 위하여 한국종축개량협회에서 1,128 두의 씨수소에 대한 3,760 두에 혈통자료를 최종적으로 이용하였다.

\section{2. 분석방법}

본 연구에서 평균 근교 및 혈연계수를 추정하기 위하여 tabular method (Emik and Terrill, 1949)를 이용하였다. 이 방법을 이용 하기 위한 알고리즘은 $\mathrm{Kim}$ 등 (2010)에서 이용된 포트란 코드를 이용하였다. Intel Visual Fortran Compiler(Window Ver. 11.1) 를 이용하여 컴파일 하였다.

\section{3. 조사항목}

본 연구에서 조사된 항목은 평균 근교 및 혈연계수, 세대간격, 유효집단크기였으며 다음과 같은 방법으로 측정하였다.

\section{(1) 평균 근교 및 혈연계수}

평균 근교 및 혈연계수는 1983년부터 2008년까지 각 연도별 씨 수소에 대하여 tabular method로 계산된 혈연행렬로 구하였다. 평 균 근교계수는 각 연도별로 씨수소에 대한 혈연행렬을 계산하여 대 각원소의 평균으로 계산하여 각 연도별 평균 근교계수를 구하였고, 평균 혈연계수는 각 연도별 씨수소에 대한 혈연행렬을 계산하여 대 각원소를 제외한 원소의 평균으로 계산하여 각 연도별 평균 혈연계 수를 구하였다.

\section{(2) 세대간격}

세대간격은 자손이 부모가 되어 새끼를 낳을 때 부모의 평균나이 이다. 총 4 가지 경로가 있는데 아비에서 아들 $\left(L_{m m}\right)$, 아비에서 딸 $\left(L_{m f}\right)$, 어미에서 아들 $\left(L_{f m}\right)$ 과 어미에서 딸 $\left(L_{f f}\right)$ 이 있다. 세대간격은 4가지 경우의 평균으로 식으로 나타내면 다음과 같다.

$$
L=\frac{L_{m m}+L_{m f}+L_{f f}+L_{f m}}{4}
$$

씨수소는 모두 수컷이므로 경로는 아비에서 아들과 어미에서 아 들 2경로만 되어서 식은 다음과 같다.

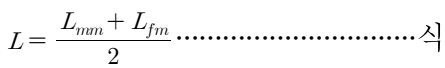

(3) 유효집단크기

유효집단크기는 1983 년부터 2008년까지 각 연도의 보증 및 후 보씨수소에 평균 근교계수의 평균에 세대간격을 곱한 세대 당 평균 근교비율을 이용하여 현재 보증 및 후보씨수소의 유효집단크기를 추정하였다. 세대 당 평균 근교비율을 이용한 유효집단크기는 다음 식에 의해 계산된다.

$$
\begin{aligned}
& N_{e}=\frac{1}{2 \times \Delta F_{L}} \\
& \Delta F_{L}=\left(\frac{\sum \Delta F_{t-1, t}}{k-1}\right) L \cdots \cdots \cdots \cdots \cdots \cdots \cdots \cdots \cdots \cdots \cdots \cdots \cdots \\
& \Delta F_{t-1, t}=\frac{F_{t}-F_{t-1}}{1-F_{t-1}}
\end{aligned}
$$

여기서, $\Delta F_{L}$ 는 세대 당 평균 근교계수, $L$ 은 세대간격, $k$ 는 고려 된 연도수, $\Delta F_{t}$ 는 $\mathrm{t}$ 년도의 근교비율, $\Delta F_{t-1}$ 는 $\mathrm{t}-1$ 년도의 근교비율 이다.

\section{결과 및 고찰}

\section{1. 평균 근교 및 혈연계수 추정}

본 연구에서 추정된 1983년부터 2008년까지 1,128두에 대한 보 증 및 후보씨수소의 각 연도별 선발된 보증 및 후보씨수소의 수, 근교된 씨수소의 수, 근교된 씨수소의 비율, 평균 근교계수, 혈연행 렬에서 총 원소 수, 혈연행렬에서 0 이 아닌 원소 수, 0 이 아닌 원 소의 비율과 평균 혈연계수는 Table 1 에 표시하였고, 근교된 개체 비율과 평균 근교계수의 차트를 Fig. 1 에 나타냈고, 0 이 아닌 원소 비율과 평균 혈연계수의 차트를 Fig. 2에 나타냈다.

근교된 씨수소의 수는 1 12두의 분포를 나타냈는데 1984년도에 처음 1두가 나왔고 1990년에 1두를 제외하고 1996년까지는 나타 나지 않았다가 1997년에 2두를 시작으로 점점 증가하여 2008년에 는 28 두 중 12 두 $(42.86 \%)$ 가 근교되었다. 평균 근교계수는 0.04 에 서 $0.97 \%$ 의 분포를 나타냈는데 1997년부터 2006년까지 비슷한 수준을 유지하다가 최근 2007년과 2008년에 각각 0.71과 $0.97 \%$ 로 증가되었다. 한우에서 Lee 등 (1992)이 추정한 평균 근교계수는 최근 2년을 제외하고 비슷한 수준 이였는데 이는 1990년에 이전의 한우에 대한 평균 근교계수를 추정하였기 때문에 2년을 제외하고 비슷한 수준으로 추정된 것으로 사료된다. 국외 다른 품종에서는 Gutiérrez 등 (2003)이 추정한 스페인의 Alistana 품종, Sørensen 등 (2005)이 추정한 덴마크의 Danish Red 품종, Parland 등 (2007)이 추정한 아일랜드의 Angus, Simmental, HolsteinFriesian 품종과 Martínez 등 (2008)이 추정한 콜롬비아의 Costeño con Cuernos, Romosinuano, Sanmartinero 3품종에 대한 평균 근교계수와 대체적으로 비슷한 수준을 나타냈고, 다른 여러 나라에 
Dang et al. ; Inbreeding Coefficient and Effective Population size in Hanwoo

Table 1. Number of inbred bulls, ratio of inbred bulls, average inbreeding coefficients, number of total scala and non-zero scala, ratio of non-zero scala and average relatedness in NRM

\begin{tabular}{|c|c|c|c|c|c|c|c|c|}
\hline Year & $\mathrm{NB}^{1)}$ & $\mathrm{NIB}^{2)}$ & $\operatorname{RIB}^{3)}(\%)$ & $\mathrm{AIC}^{4)}(\%)$ & $\mathrm{NTS}^{5)}$ & $\mathrm{NNS}^{6}$ & $\operatorname{RNS}^{7}(\%)$ & $\mathrm{AR}^{8)}(\%)$ \\
\hline 1983 & 51 & 0 & 0 & 0 & 2,550 & 10 & 0.38 & 0.10 \\
\hline 1984 & 62 & 1 & 1.61 & 0.40 & 3,782 & 40 & 1.06 & 0.22 \\
\hline 1985 & 53 & 0 & 0 & 0 & 2,756 & 28 & 1.02 & 0.25 \\
\hline 1986 & 49 & 0 & 0 & 0 & 2,352 & 32 & 1.36 & 0.31 \\
\hline 1987 & 44 & 0 & 0 & 0 & 1,892 & 58 & 3.07 & 0.60 \\
\hline 1988 & 44 & 0 & 0 & 0 & 1,892 & 102 & 5.39 & 1.30 \\
\hline 1989 & 37 & 0 & 0 & 0 & 1,332 & 44 & 3.30 & 0.66 \\
\hline 1990 & 36 & 1 & 2.78 & 0.09 & 1,260 & 44 & 3.49 & 0.68 \\
\hline 1991 & 39 & 0 & 0 & 0 & 1,482 & 90 & 6.07 & 0.95 \\
\hline 1992 & 30 & 0 & 0 & 0 & 870 & 76 & 8.74 & 1.44 \\
\hline 1993 & 39 & 0 & 0 & 0 & 1,482 & 82 & 5.53 & 0.82 \\
\hline 1994 & 29 & 0 & 0 & 0 & 812 & 140 & 17.24 & 1.56 \\
\hline 1995 & 37 & 0 & 0 & 0 & 1,332 & 150 & 11.26 & 1.20 \\
\hline 1996 & 31 & 0 & 0 & 0 & 930 & 120 & 12.90 & 1.51 \\
\hline 1997 & 61 & 2 & 3.28 & 0.04 & 3,599 & 1,064 & 29.07 & 3.13 \\
\hline 1998 & 62 & 5 & 8.06 & 0.29 & 3,782 & 1,044 & 27.60 & 2.62 \\
\hline 1999 & 50 & 4 & 8.00 & 0.23 & 2,450 & 778 & 31.76 & 2.94 \\
\hline 2000 & 51 & 3 & 5.88 & 0.21 & 2,550 & 982 & 38.51 & 2.76 \\
\hline 2001 & 40 & 3 & 7.50 & 0.23 & 1,560 & 572 & 36.67 & 1.75 \\
\hline 2002 & 37 & 5 & 13.51 & 0.17 & 1,332 & 740 & 55.56 & 2.17 \\
\hline 2003 & 34 & 4 & 11.76 & 0.11 & 1,122 & 714 & 63.64 & 4.50 \\
\hline 2004 & 50 & 4 & 8.00 & 0.16 & 2,450 & 1,772 & 72.33 & 3.38 \\
\hline 2005 & 40 & 9 & 22.50 & 0.19 & 1,560 & 1,316 & 84.36 & 4.53 \\
\hline 2006 & 46 & 12 & 26.09 & 0.21 & 2,070 & 1,832 & 88.50 & 4.56 \\
\hline 2007 & 47 & 6 & 12.77 & 0.71 & 2,162 & 1,634 & 75.58 & 6.82 \\
\hline 2008 & 28 & 12 & 42.86 & 0.97 & 756 & 690 & 91.27 & 5.23 \\
\hline
\end{tabular}

${ }^{1)} \mathrm{NB}:$ Number of bulls; ${ }^{2)} \mathrm{NIB}$ :Number of inbred bulls; ${ }^{3} \mathrm{RIB}:$ Ratio of inbred bulls; ${ }^{4)}$ AIC:Average inbreeding coefficients; ${ }^{5)} \mathrm{NTS}$ :Number of total scala-except diagonal scala of numerator relationship matrix; ${ }^{6} \mathrm{NNS}$ :Number of non-zero scala; ${ }^{7}$ RNS:Ratio of non-zero scala ${ }^{8)} \mathrm{AR}$ :Average relatedness

대한 품종에 대해서 낮게 추정되었다.

0 이 아닌 원소의 비율은 0.38 에서 $91.27 \%$ 의 분포를 나타냈고 2001년 이전은 40\% 보다 낮았지만 2002년부터 높아져서 2008년 최근에는 $91.27 \%$ 로 거의 모든 씨수소들이 혈연관계가 있었다. 평 균혈연계수는 0.10 에서 $6.82 \%$ 의 분포를 나타냈다. 한우에 대해 추 정된 평균 혈연계수가 미흡하여 국외 다른 품종과 비교를 하였다. Gutiérrez 등 (2003)이 추정한 스페인의 8개 품종에 대한 평균 혈 연계수, Hammami 등 (2007)이 추정한 튀니지와 룩셈부르크의 Holstein 품종에 대한 평균 혈연계수와 Martínez 등 (2008)이 추 정한 콜롬비아의 4 개 품종에 대한 평균 혈연계수보다 다소 높게 추정되었다.

이 결과는 국가적으로 보증 및 후보씨수소에 대해 근교를 피하기
위한 교배의 노력으로 아직까지 국외 다른 품종들에 비해 적은 평 균 근교계수를 보인다고 사료된다. 하지만 한우개량이 1990년대 이전에는 개량의 정착기로 혈통관리 및 자료관리가 부족하여 1996 년까지 근교계수가 발생되었어도 나타나지 않은 것으로 사료되고 점차 혈통자료가 보충되면서 1997년부터는 근교계수가 발생하기 시작된 것으로 사료된다. 만약 지금까지 씨수소의 모든 혈통자료가 완벽하다면 보증 및 후보씨수소의 평균 근교계수는 더 높아질 수 있을 것으로 사료된다. 그리고 보증 및 후보씨수소의 선발에서도 한우개량사업소, 도 축산연구센터, 개량농가 및 육종농가에서 제한 되게 선발하기 때문에 서로 관련된 개체를 선발할 확률이 다른 외 국품종에 비해 높아서 평균 혈연계수가 높게 추정되었다고 사료된 다. 농가에 정액을 공급하는 씨수소들의 평균 혈연계수가 높아진다 


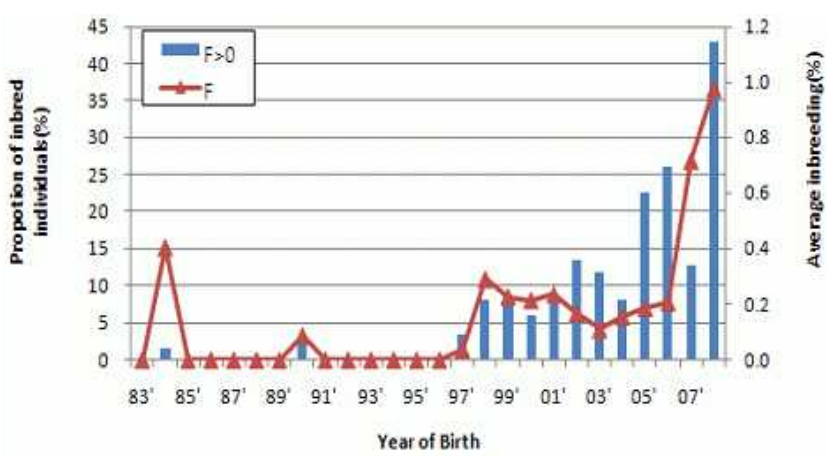

Fig. 1. Average inbreeeding coefficients (\%) and proportion of animals (\%) with inbreeding coefficients greater than zero of proven and young bulls from 1983 to 2008 .

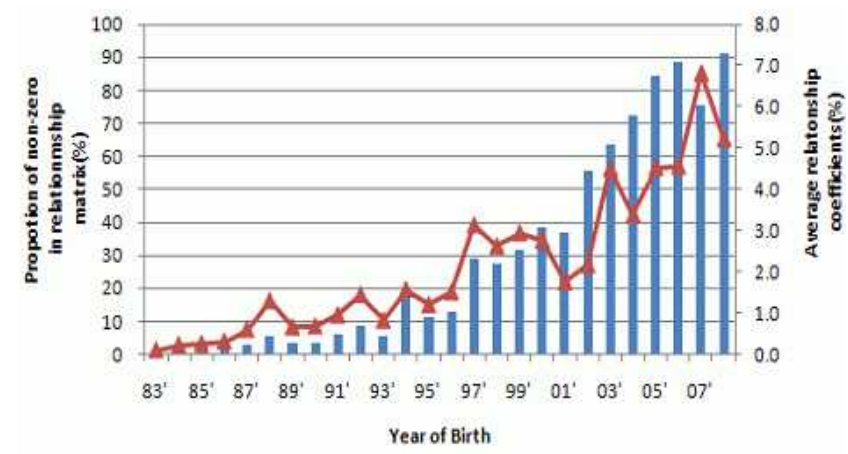

Fig. 2. Average relatedness (\%) and proportion of nonzero relationship coefficients in NRM (\%) of proven and young bulls from 1983 to 2008 .

면 정액을 공급받는 농가에서 근교된 개체가 발생할 확률은 더 높 아질 것으로 사료되고, 평균 근교계수가 높아진다면 근교퇴화의 영 향을 받을 수 있을 것으로 사료된다.

Table 2. Estimated generation interval $(L)$ by birth year

\section{2. 세대간격 추정}

본 연구에서 추정된 1983 년부터 2008년까지 1,128 두에 대한 보 증 및 후보 씨수소의 아비에서 아들 $\left(L_{m m}\right)$ 의 세대간격, 어미에서 아 들 $\left(L_{f m}\right)$ 의 세대간격과 평균 세대간격 $(L)$ 을 Table 2 에 표시하였다. 아비에서 아들 $\left(L_{m m}\right)$ 의 세대간격범위는 약 3 (2.97)년에서 9 (8.54)년이고, 평균은 약 7 (6.95)년으로 추정되었다. 어미에서 아 들 $\left(L_{f m}\right)$ 의 세대간격범위는 약 $2(1.79)$ 년에서 7 (6.96)년이고, 평균 은 약 5 (5.17)년으로 추정되었다. 평균세대간격 $(L)$ 의 범위는 약 2 (2.38)년에서 7(7.23)년으로 추정되었고, 평균은 약 $6(6.06)$ 년으로 추정되었다. 이 결과는 1983 년과 1984 년은 각각 약 2 (2.38)년과 4 (3.83)년으로 낮게 추정되었는데 이는 한우 씨수소 선발을 위한 당-후대검정체계를 1985년부터 시작하였기 때문에 1985년 이전 에는 씨수소를 표현형으로 선발하여 세대간격이 적은 씨수소가 선 발될 수도 있어서 낮게 추정되었다고 사료된다. 그리고 한우는 씨 수소를 약 5 년간 당·후대검정체계를 거쳐 선발하여 약 4 년간 (평 균 2년 이용) 정액을 생산하는데 이용하므로 보통 세대간격이 7년 정도 된다. 그러므로 아비에서 아들 $\left(L_{m m}\right)$ 은 씨수소이기 때문에 7 년으로 비슷하게 추정되었지만 암소는 5 년으로 추정되었는데 아직 암소는 국가단위로 검정을 하지 않기 때문에 비교적 낮게 추정되었 다고 사료된다.

\section{3. 유효집단크기 추정}

1983년부터 2008년까지 1,128 두에 대한 보증 및 후보씨수소에 대한 유효집단크기를 Table 3 에 표시하였다. 세대 당 평균 근교비 율은 $0.0374 \%$ 로 추정되었고 세대간격은 6.06 으로 추정되어서 유 효집단크기는 220 두로 추정되었다. 아직 국내 한우에 대한 유효집 단크기를 추정하는 연구가 미흡하여 외국 소품종에 대한 유효집단 크기와 비교를 하였다. Nomura 등 (2001)은 일본 흑우에 대한 유

\begin{tabular}{cccc||cccc}
\hline \multirow{2}{*}{ Year } & \multicolumn{3}{c||}{ Generation interval } & \multirow{2}{*}{ Year } & \multicolumn{3}{c}{ Generation interval } \\
\cline { 2 - 3 } & sire to son & dam to son & Average & & sire to son & dam to son & Average \\
\hline \hline 83 & 2.97 & 1.79 & 2.38 & 96 & 7.31 & 5.48 & 6.39 \\
84 & 4.56 & 3.11 & 3.83 & 97 & 7.86 & 5.22 & 6.54 \\
85 & 6.67 & 4.37 & 5.52 & 98 & 7.93 & 4.60 & 6.27 \\
86 & 7.21 & 6.32 & 6.77 & 99 & 7.61 & 6.01 & 6.81 \\
87 & 8.54 & 4.04 & 6.29 & 00 & 7.21 & 4.44 & 5.82 \\
88 & 6.95 & 6.06 & 6.51 & 01 & 6.83 & 4.44 & 5.63 \\
89 & 6.15 & 5.88 & 6.01 & 02 & 6.88 & 4.86 & 5.87 \\
90 & 7.11 & 5.86 & 6.48 & 03 & 6.53 & 5.19 & 5.86 \\
91 & 7.44 & 5.45 & 6.45 & 04 & 6.82 & 4.68 & 5.75 \\
92 & 7.51 & 6.96 & 7.23 & 05 & 6.62 & 4.74 & 5.68 \\
93 & 7.09 & 6.82 & 6.95 & 06 & 6.98 & 5.27 & 6.12 \\
94 & 7.07 & 6.29 & 6.68 & 07 & 7.44 & 5.73 & 6.59 \\
95 & 7.20 & 5.75 & 6.48 & 08 & 8.12 & 5.13 & 6.63 \\
\hline
\end{tabular}


Table 3. The rates of increase in inbreeding coefficients $\left(F_{x}\right)$ and the estimates of generation interval (L) in each year and the effective population size $\left(\mathrm{N}_{\mathrm{e}}\right)$

\begin{tabular}{|c|c|c|c|}
\hline Year & $F_{x}$ & \multicolumn{2}{|c|}{ Generation interval } \\
\hline 1983 & - & \multicolumn{2}{|r|}{2.38} \\
\hline 1984 & 0.4032 & \multicolumn{2}{|r|}{3.83} \\
\hline 1985 & -0.4049 & \multicolumn{2}{|r|}{5.52} \\
\hline 1986 & 0 & \multicolumn{2}{|r|}{6.77} \\
\hline 1987 & 0 & \multicolumn{2}{|r|}{6.29} \\
\hline 1988 & 0 & \multicolumn{2}{|r|}{6.51} \\
\hline 1989 & 0 & \multicolumn{2}{|r|}{6.01} \\
\hline 1990 & 0.0868 & \multicolumn{2}{|r|}{6.48} \\
\hline 1991 & -0.0869 & \multicolumn{2}{|r|}{6.45} \\
\hline 1992 & 0 & \multicolumn{2}{|r|}{7.23} \\
\hline 1993 & 0 & \multicolumn{2}{|r|}{6.95} \\
\hline 1994 & 0 & \multicolumn{2}{|r|}{6.68} \\
\hline 1995 & 0 & \multicolumn{2}{|r|}{6.48} \\
\hline 1996 & 0 & \multicolumn{2}{|r|}{6.39} \\
\hline 1997 & 0.0384 & \multicolumn{2}{|r|}{6.54} \\
\hline 1998 & 0.2515 & \multicolumn{2}{|r|}{6.27} \\
\hline 1999 & -0.0634 & \multicolumn{2}{|r|}{6.81} \\
\hline 2000 & -0.0121 & \multicolumn{2}{|r|}{5.82} \\
\hline 2001 & 0.0200 & \multicolumn{2}{|r|}{5.63} \\
\hline 2002 & -0.0656 & \multicolumn{2}{|r|}{5.87} \\
\hline 2003 & -0.0599 & \multicolumn{2}{|r|}{5.86} \\
\hline 2004 & 0.0472 & \multicolumn{2}{|r|}{5.75} \\
\hline 2005 & 0.0303 & \multicolumn{2}{|r|}{5.68} \\
\hline 2006 & 0.0195 & \multicolumn{2}{|r|}{6.12} \\
\hline 2007 & 0.5099 & \multicolumn{2}{|r|}{6.59} \\
\hline \multirow[t]{2}{*}{2008} & 0.2593 & \multicolumn{2}{|r|}{6.63} \\
\hline & $1983 \sim 2008$ & 1999 2008 & 2004 2008 \\
\hline $\mathrm{F}(\%)^{1)}$ & 0.0374 & 0.0685 & 0.1732 \\
\hline $\mathrm{L}^{2)}$ & 6.06 & 6.08 & 6.15 \\
\hline $\mathrm{N}_{\mathrm{e}}^{3)}$ & 220.46 & 120.05 & 46.90 \\
\hline
\end{tabular}

${ }^{1)} \mathrm{F}(\%)$ : average of the rate of increase in inbreeding coefficients;

${ }^{2)} \mathrm{L}$ : generation interval; ${ }^{3)} \mathrm{N}_{\mathrm{e}}$ : effective population size.

효집단크기를 14 52두, Gutiérrez 등 (2003)은 스페인 8품종에 대 한 유효집단크기를 21 123두, Cleveland 등 (2005)은 미국 Hereford 품종에 대한 유효집단크기를 85두, Sørensen 등 (2005) 은 덴마크 Holstein 품종에 대한 유효집단크기를 49 87, Bozzi 등 (2006)은 이탈리아 3품종에 대한 유효집단크기를 122 138두, Maiwashe 등 (2006)은 아프리카 4품종에 대한 유효집단크기를 108 165두, Parland 등 (2007)은 아일랜드 3품종에 대한 유효집단 크기를 64 127, Martínez 등 (2008)은 콜롬비아 3품종에 대한 유 효집단크기를 27 143두로 추정하여 다른 외국품종보다 높게 추정
되었고, Martínez 등 (2008)이 추정한 콤롬비아 Blanco Orejinero 품종 260 두보다는 낮게 추정되었다. 이는 아직 우리나라가 보증 및 후보씨수소에 대해 근교를 피하기 위한 교배를 하여 평균 근교 비율이 낮게 추정되어 유효집단크기가 다른 품종에 비하여 높게 추 정되었다고 사료된다. 하지만 최근 5년간 평균 근교비율로 계산한 유효집단크기는 47두로 작게 추정되었다. 이는 유효집단크기를 씨 수소의 평균 근교비율로 추정하므로 최근 2 년 동안 근교계수의 급 격한 증가 때문이라고 사료된다.

유효집단크기에 대하여 Meuwissen (1999)은 집단의 적응도가 줄어들 때를 유효집단크기가 100 이하라고 제안하였고, 미국 $\mathrm{FAO}$ (2004)에서 가축의 유전적 다양성을 위하여 유효집단크기를 최소 50 을 유지하라고 권고하였다. 아직 평균 근교계수는 아직 낮은 수 준이라서 근교에 대한 영향은 적게 나타날 수 있지만, 최근 2년간 평균 근교계수의 급격한 증가로 유효집단크기도 작게 추정되었고, 평균 혈연계수도 증가하는 추세이다. 이를 보완하기 위하여 보증씨 수소 선발시 후대검정우의 도체성적에 의한 유전능력평가 자료의 활용뿐만 아니라, 근교 및 혈연계수를 고려하고 한우의 유전적 다 양성의 보존을 위하여 현행의 보증씨수소 두수를 증가시켜 유효집 단크기를 높여야 될 필요성이 있다고 사료된다.

\section{요 약}

본 연구는 지금까지 보증 및 후보씨수소로 선발된 씨수소에 대하 여 연도별 평균 근교 및 혈연계수를 추정하고 씨수소의 유효집단크 기를 추정하여 현재 한우개량 체계의 문제를 도출하여 발전된 대안 을 제시하고자 실시하였다. 분석에 이용된 자료는 한우개량사업소 로부터 1983년부터 2008년까지 1,128두의 당-후대검정 씨수소자 료와 한국종축개량협회로부터 3,760 두에 대한 혈통자료를 받아 이 용하였다. 보증 및 후보씨수소의 평균 근교계수는 0.04 에서 $0.97 \%$ 의 분포로 추정되었으며, 평균 혈연계수는 0.10 에서 $6.82 \%$ 의 분포 로 추정되었다. 유효집단 크기는 1983년부터 2008년까지 26년간 평균 근교비율을 이용하였을 때 220 두로 추정되었다. 근교수준은 최근 2 년간 급격히 증가하였고, 평균 혈연계수 역시 점차 증가하는 추세이다. 유효집단크기도 최근 5년의 근교비율로 추정하였을 때 47두로 작게 추정되었다. 보증씨수소 선발시 후대검정우의 도체성 적에 의한 유전능력평가 자료의 활용뿐만 아니라, 근교 및 혈연계 수를 고려하고 한우의 유전적 다양성의 보존과 근교를 피하기 위하 여 현행의 보증씨수소 두수를 증가시켜 유효집단크기를 높여야 될 필요성이 있다고 사료된다.

(주제어: 근교계수, 유효집단크기, 한우씨수소)

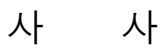

이 논문은 2010년도 충북대학교 학술연구지원사업의 연구비 지 원에 의하여 연구되었음. 


\section{인 용 문 헌}

Bozzi, R., Franci, O., Forabosco, F., Pugliese, C., Crovetti, A. and Filippini, F. 2006. Genetic variability in three Italian beef cattle breeds derived from pedigree information. Ital. J. Anim. Sci. 5:129-137.

Cleveland, M. A., Blackburn, H. D., Enns, R. M. and Garrick, D. J. 2005. Changes in inbreeding of U. S. Herefords during the twenitieth century. J. Anim. Sci. 83:992-1001.

Emik, L. O. and Terrill, C. R. 1949. Systematic procedures for calculating inbreeding coefficients. J. Hered. 40:51-55.

Food and Agriculture Organisation (FAO). 2004. Secondary guidelines for development of national farm animal genetic resources management plans. Management of small populations at risk. J. A. Woolloams, G. P. Gwaze, T. H. E. Meuwissien, D. Planchenault, J. P. Renard, M. Thibier and H. Wagner, ed Food and Agriculture Organisation of the United Nations.

Gutiérrez, J. P., Altarriba, J., Díaz, C., Quintanilla, R., Cañón, J. and Piedarafita, J. 2003. Pedigree analysis of eight Spanish beef cattle breeds. Genet. Sel. Evol. 35:43-63.

Hammami, H., Croquet, C., Stoll, J., Rekik, B. and Gengler, N. 2007. Genetic diversity and joint-pedigree analysis of two importing Holstein populations. J. Dairy Sci. 90:3530-3541.

Kim, N. S., Lee, J. J., Dang, C. G., Jeoung, Y. H. and Won, Y. S. 2010. A study on the relationship of active proven bulls of Hanwoo(Korean cattle). Bulletin of the Animal Biotechnology. 3:1-7.
Lee, M. Y., Seol, D. S., Park, S. H. and Lee, S. G. 1992. Estimation of inbreeding coefficients in Hanwoo and Holstein. Korean Society of Animal Science and Technology. C9219.

Maiwashe, A., Nephawe, K. A., van Westhuizen, R. R., Mostert, B. E. and Theron, H. E. 2006. Rate of inbreeding and effective population size in four major South African dairy cattle breeds. S. Afr. J. Anim. Sci. 36(1):50-57.

Martínez, R. A., Grarcía, D., Gallego, J. L., Onofre, G., Pérez, J. and Cañón, J. 2008. Genetic variability in Colombian Creole cattle populations estimated by pedigree information. J. Anim. Sci. 86:545-552

Meuwissen, T. H. E. 1999. Operation of conservation schemes. Pages 91-112 in Genebanks and the Conservation of Farm Animal Genetic Resources. J. K. Oldenbreoek, ed. DLOP Inst. For Anim. Sci and Health, Lelystad, The Netherlands.

Nomura, T., Honda, T. and Mukai, F. 2001. Inbreeding and effective population size of Japanese black cattle. J. Anim. Sci. 79:366370.

Parland, S. Mc., Kearney, J. F., Rath, M. and Berry, D. P. 2007b. Inbreeding trends and pedigree analysis of Irish dairy and beef cattle populations. J. Anim. Sci. 85:322-331.

Sørensen, A. C., Sørensen, M. K. and Berg, P. 2005. Inbreeding in Danish dairy cattle breeds. J. Dairy Sci. 88:1865-1872.

Weigel, K. A. 2001. Controlling inbreeding in modern breeding programs. J. Dairy Sci. 84:177-184.

(Received Jan. 26, 2011; Revised Mar. 30, 2011; Accepted Apr. 10, 2011) 